\title{
Hybrid Short Glass Fibre Composites Reinforced with Silica Micro- particles
}

\author{
Lenir de Abreu Júnior ${ }^{1}$, Rodrigo Teixeira Santos Freire ${ }^{1}$, Pablo Resende Oliveira ${ }^{1,2}$, André Luis Chris- \\ toforo $^{3}$, Carlos Thomas Garcia ${ }^{4}$, Gilberto García del Pino ${ }^{5}$, Tulio Hallak Panzera ${ }^{1 *}$ \\ ${ }^{1}$ Centre for Innovation and Technology in Composite Materials - CIT ${ }^{\mathrm{e}} \mathrm{C}$, Federal University of São João del Rei-UFSJ, \\ Brazil. E-mail: panzera@ufsj.edu.br \\ ${ }^{2}$ Institute of Sustainable Systems Engineering, Albert-Ludwigs Universität Freiburg, Freiburg im Breisgau, Germany \\ ${ }^{3}$ Federal University of São Carlos-UFSCar, Brazil \\ ${ }^{4}$ LADICIM (Laboratory of Materials Science and Engineering), Universidad de Cantabria, Spain \\ ${ }^{5}$ State University of Amazonas, Manaus, Brazil
}

\section{ABSTRACT}

This work investigates epoxy composites reinforced by randomly oriented, short glass fibres and silica microparticles. A full-factorial experiment evaluates the effects of glass fibre mass fraction (15 and $20 \mathrm{wt} \%$ ) and length (5 and $10 \mathrm{~mm})$, and the mass fraction of silica microparticles (5 and $10 \mathrm{wt} \%$ ) on the apparent density and porosity, as well as the compressive and tensile strength and modulus of the hybrid composites. Hybrid epoxy composites present significantly higher tensile strength (9\%) and modulus (57\%), as well as compressive strength (up to 15\%) relative to pure epoxy. Keywords: Hybrid Composites; Silica Microparticles; Short Glass Fibres; Design of Experiments; Mechanical and Physical Characterisation

\section{Introduction}

Short glass fibre-reinforced composites (SGFCs) have been widely used in several applications, such as the automotive and construction industries, boats, sports equipment, pipes and storage tanks owing to their mechanical properties conjugated to ease and low costs of fabrication, as well as design flexibility ${ }^{[1]}$. These composites, however, provide less strength and stiffness relative to their continuous fibre counterparts.

Micro- and nanoparticles can further reinforce SGFCs, providing an increase in the stiffness and fibre-matrix adhesion, and acting as crack arresting agents. These fillers can also reduce fabrication costs ${ }^{[2]}$ and the density of the composites, increasing the specific stiffness of the resulting material ${ }^{[3]}$.

The incorporation of rigid ceramic fillers may also enhance the erosion wear resistance of fibre-reinforced polymeric composites. A variety of aggregates has been used, such as cement, clay, carbon nanotube and silica particles. The performance of hybrid particle-fibre-reinforced composites is also dependent on fibre characteristics, such as aspect ratio (defined as the ratio between fibre length and diameter) and fibre volume fraction, as well as the strength and strain to failure of the fibre in comparison to the matrix. Fibres of high aspect ratio provide composites with higher tensile strength ${ }^{[1]}$.

Several studies have investigated the potential reinforcement of micro- and nano- particles in continuous fibre-reinforced polymeric composites. Santos et al. ${ }^{[3]}$ reported that the inclusion of $2 \mathrm{wt} \%$ silica nanoparticles in plain-weave glass fibre-reinforced epoxy composites led to increased tensile (flexural) modulus in $11.6 \%$

Copyright (C) 2020 Lenir de Abreu Júnior et al.

doi: 10.24294/jpse.v3i1.1191

EnPress Publisher LLC.This work is licensed under the Creative Commons Attribution-NonCommercial 4.0 International License (CC BY-NC 4.0). http://creativecommons.org/licenses/ by/4.0/ 
(13.2\%). The particles were functionalised with poly-diallyldimethylammonium chloride (PDDA) to enhance their dispersion in the polymeric matrix. The tensile strength was also $28.8 \%$ higher. The authors attribute this effect to the reduction in crack propagation due to the high specific surface of nanoparticles. Silica microparticles $(3 \mathrm{wt} \%)$ also enhanced the flexural modulus in $11.3 \%$ but reduced the tensile strength. The flexural strength, however, decreased with the inclusion of both nano- and microparticles. It is worth noting that microparticles led to a smaller reduction in flexural strength.

Detomi et al. ${ }^{[4]}$, in contrast, investigated the incorporation of silica and silicon carbide microparticles at 10 and $20 \mathrm{wt} \%$ mass fractions in different parts (whole composite or only in the side under compressive loads) of epoxy composites reinforced by cross-ply glass fibre fabrics. The authors observed that the presence of ceramic microparticles in the upper beam side under compressive loads increased by $110 \%$ the flexural strength of the composites. Moreover, since the particles did not alter the density of the material significantly, the specific flexural strength also increases by $112 \%$. However, microparticles reduced the flexural modulus, even though higher values were obtained with particles added only in the side of the sample subjected to compressive loads. Torres et $a l .^{[5]}$ investigated the flexural and impact behaviour of unidirectional glass fibre laminates with cement or silica microparticles added only in the upper beam side of the laminates subjected to compressive loads. The inclusion of $5 \mathrm{wt} \%$ of silica (cement) microparticles increased the flexural strength up to $36 \%$ (46\%) depending on the number of layers used. The flexural modulus increased by $20 \%(29 \%)$ and the impact energy by $10 \%$ (40\%) upon the presence of $5 \mathrm{wt} \%$ silica (cement) microparticles compared to the composite without particles.

Pande and Sharma ${ }^{[6]}$ investigated the hybrid reinforcement provided by E-glass fibres (average diameter of $12 \mu \mathrm{m})$ and silane-treated A glass particles $(5-12 \mu \mathrm{m})$ in a polypropylene matrix. These authors have observed a synergistic effect between glass particles and fibres, which leads to higher flexural modulus and strength of hybrid microparticle-fibre-reinforced composites relative to fibre-only or particle-only effects. Oliveira et al. ${ }^{[7]}$ also reported a slight increase in flexural modulus of untreat- ed short-coir epoxy composites reinforced with cement microparticles. However, no improvements were observed in flexural strength, neither for $\mathrm{NaOH}$-treated nor untreated coir fibres ${ }^{[7]}$. Similar results were also reported by Margotti et al. ${ }^{[8]}$ upon the inclusion of cement particles $(10 \mathrm{wt} \%)$ in short sisal fibre-reinforced epoxy composites.

Short-fibre-reinforced materials present, however a more complex microstructure, with additional parameters that influence their mechanical performance such as fibre volume fraction, fibre length and aspect ratio, and fibre orientation $^{[1,9,10]}$. Fu et al. ${ }^{[1]}$ observed that the tensile strength of short glass and carbon fibre-reinforced polypropylene composites depend mainly on the mean fibre length (or aspect ratio). The tensile modulus is more dependent on fibre volume fraction. The tensile strength and the strain at failure, for example, increase for higher aspect ratio of the fibres. In contrast, the strain at failure decreases for higher fibre volume fractions. Under tensile loading, the cracks initiate at the fibre ends, which concentrate stress in the order of 10 times or higher ${ }^{[1,9]}$. Curtis et al. ${ }^{[9]}$ proposed that such cracks progressively weaken the composite, developing first at the longer, more aligned fibres, and gradually spreading to shorter, less aligned ones. Fibre bridging may prevent the further opening and propagation of these cracks, up to a point in which the crack density in a cross-section is so high that fibre bridging can no longer support the load and fracture takes place.

Srivastava ${ }^{[11]}$ investigated the inclusion of fly ashes into short and short-random glass fibre-reinforced epoxy composites. The author reported that the tensile strength increased and the elongation at break decreased for higher fibre volume fractions. Fly ash particles act as a barrier to crack growth, improving the fracture toughness of short glass fibre composites. The fracture surface energy also increased with higher fibre volume fraction: tensile strength and fracture toughness of fly-ash-short glass fibre epoxy composites can be improved, especially by resin-coating the fibres before cutting and adding them into the polymeric mixture. The microstructure of the composites also affects the fracture toughness, as well as microstructural phenomena, such as fibre pull-out, delamination and stress relaxation related to local inhomogeneities ${ }^{[12]}$. Reis and Ferreira also reported an in- 
crease of up to $29 \%$ and $13 \%$ in the fracture toughness of epoxy polymer concrete reinforced with short carbon and glass fibres respectively ${ }^{[13]}$.

The incorporation of particles in continuous fibre-reinforced composites has been exhaustively investigated. However, scarce literature is available on the hybridisation of short-random fibres and microparticles. To the best of these authors' knowledge, this report represents the first attempt to conjugate short glass fibres and monosized silica microparticles. A robust statistical analysis based on a full-factorial design of experiments (DoE) is used to identify the effect of glass fibre mass fraction and length, and the amount of silica microparticles on the apparent density and porosity, compressive and tensile strength and modulus of the hybrid composites.

\section{Materials and methods}

\subsection{Materials}

The matrix phase is composed of the epoxy system Araldite GY 279 and catalyser Aradur 2963, supplied by Huntsman (Brazil). Unidirectional glass fibres (roving
ME 3020 4000) and silica microparticles (30-45 $\mu \mathrm{m})$ were respectively provided by Owens Corning and Moinhos Gerais Mining Company (Brazil).

\subsection{Manufacturing process}

Fibres are cut into two lengths ( 5 and $20 \mathrm{~mm}$ ) to obtain two aspect ratios (10 and 20) that could be reproduced in industrial scale. The continuous fibre roving is shredded into short fibres using a hydraulic paper-cutter (Craftsman, Figure 1.a). Longer strands are attached to a paper sheet before cutting (Figure 1.b) to ensure fibres of uniform length (Figure 1.c). The fibre roving has approximately $180 \mu \mathrm{m}$, as shown in Figure 1d, obtained through backscattered secondary-electron microscopy.

The resin and catalyser are mixed for $5 \mathrm{~min}$ in the proportion provided by the supplier (100:42, respectively). Silica microparticles are previously oven-dried for 3 hours, and then sieved and hand-mixed into the epoxy polymer for 5 minutes for proper homogenisation and to avoid the agglomeration of particles (Figure 2.a). Short glass fibres are then added and hand-mixed to ensure the dispersion of the reinforcement phases (see Figures 2.b and 2.c).

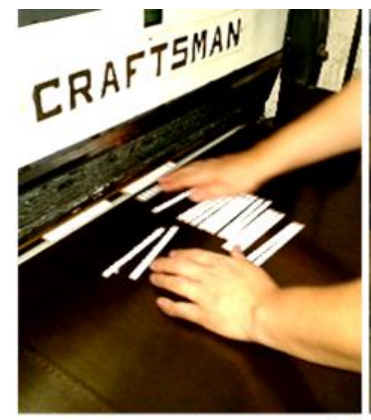

(a)

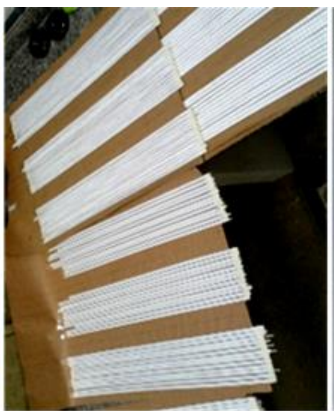

(b)

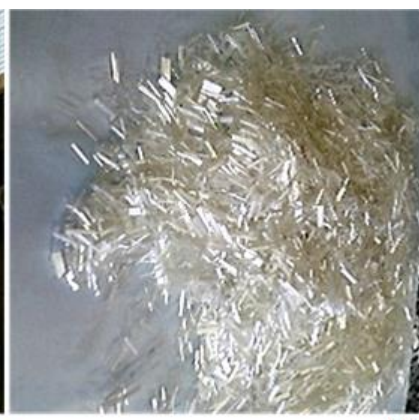

(c)

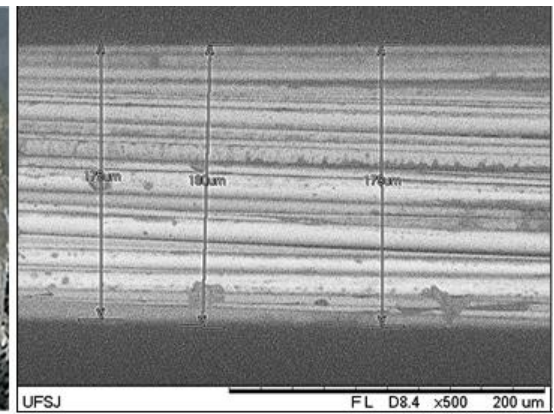

(d)

Figure 1. Shredding process (a) of continuous fibres covered by A4 paper (b) into glass fibre whiskers (c) and SEM image of the fibre roving.

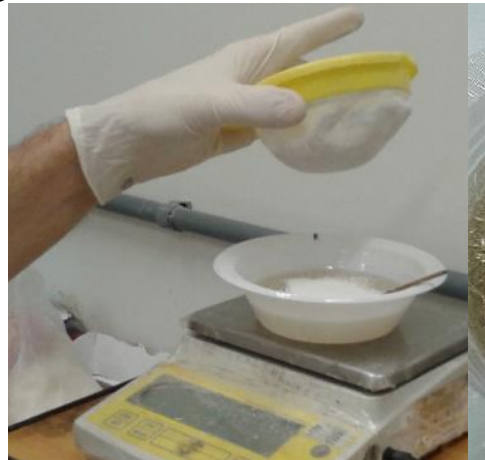

(a)

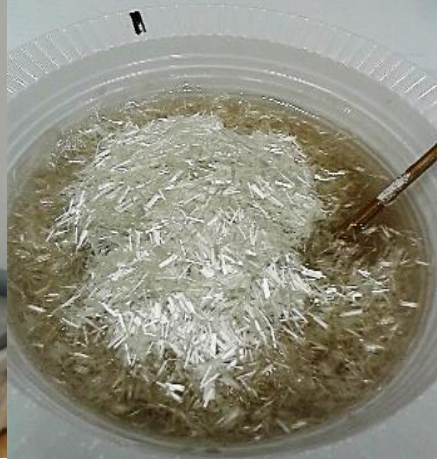

(b)

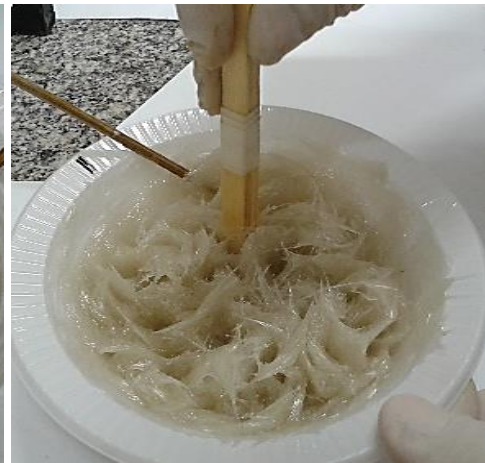

(c)

Figure 2. Hybrid composites preparation process showing (a) sieved silica and (b) short fibres incorporation and (c) mixing. 

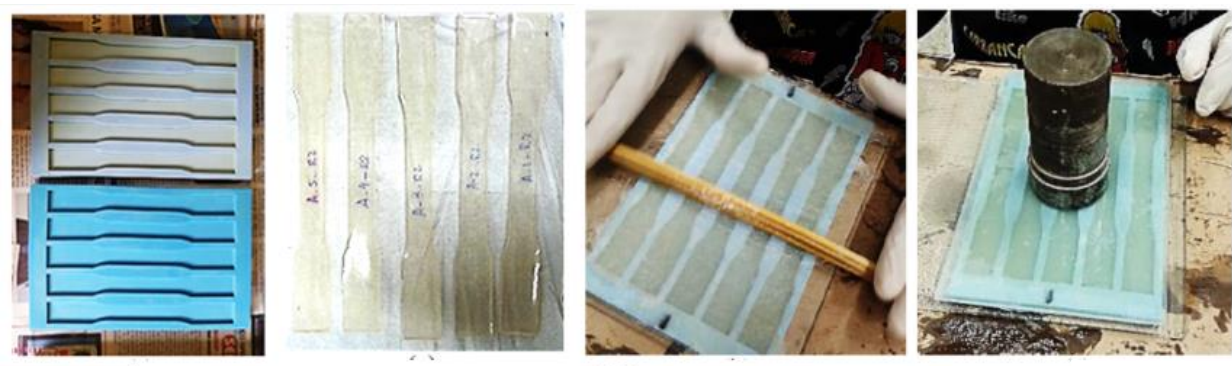

(a)
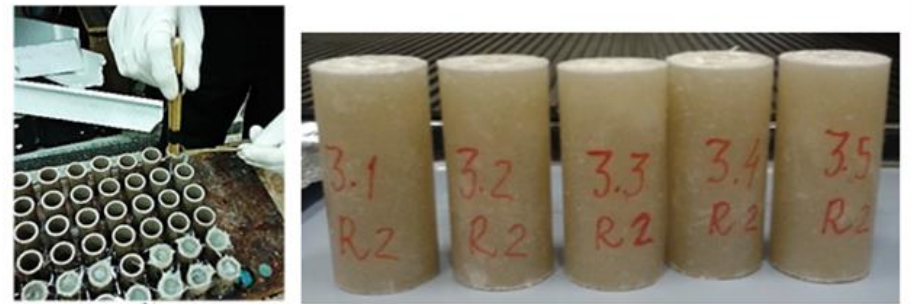

(b)

Figure 3. Fabrication of samples: (a) dog-bone samples for tensile tests and (b) cylindrical samples for compressive and physical tests.

A demoulding oil (Renlease QZ5111, Huntsman-Brazil) previously coats the moulds to ensure better surface finishing. The polymeric mixture is poured into the silicone moulds on a vibrating table to reduce porosity and voids in the samples. Dog-bone and cylindrical samples are fabricated, for tensile and compressive/physical tests, respectively (Figure 3). A fixed weight $(30 \mathrm{~N})$ on a glass plate is laid on dog bone moulds for 30 minutes for better surface finishing. Samples cure for seven days at room temperature $\left(\sim 25^{\circ} \mathrm{C}\right.$, $55 \% \mathrm{RH})$. The sizes of the samples are based on the respective ASTM standards ${ }^{[14,15]}$. Cylindrical samples for compressive tests are faceted on a lathe to ensure the parallelism of the faces.

\subsection{Statistical analysis}

A full factorial experiment $\left(2^{3}\right)$ is performed to investigate the effects of the factors (levels) silica particle amount (5 and $10 \mathrm{wt} \%$ ), glass fibre length (5 and $10 \mathrm{~mm}$ ) and amount (15 and $20 \mathrm{wt} \%$ ) on physical and mechanical properties of the fabricated composites. The mass fraction levels of silica particles are based on previous studies $^{[2,3,4,16]}$. The eight experimental conditions are presented in Table 1. The mass fraction of the epoxy matrix phase varies from 70 to $80 \%$ according to the fibre mass fraction of particles and fibres. The apparent density and porosity, the compressive and tensile moduli and strengths are investigated.

Five samples are fabricated for each experimental condition, with two replicates running a total of 90 samples per test. A reference condition consisting of pure epoxy polymer is also considered for comparison. The statistical analysis of the data is performed via Analysis of Variance (ANOVA) using the Minitab 17 software. ANOVA is used to establish the statistical significance of the effects of factors and their interactions on the physical and mechanical responses considering a 95\% confidence interval ${ }^{[17]}$. The interaction among factors occurs when the effect of one factor on a particular response depends on the level of other factors. In this case, the effects of such factors should be interpreted via interaction plots. The indicator of the significance of factors and interactions within the confidence interval is a $\mathrm{P} \leq \alpha$. The parameter $\alpha$ (the so-called significance level, fixed at 0.05 in this study) stands for the risk of stating that the effect of a factor (or interaction of factors) is significant when, in fact, it is not. The P-value, by its turn, is the smallest significance level at which the conclusions achieved would still be valid. The validity of the ANOVA is based on the normality of the underlying probability distribution of the analysed data. The Anderson-Darling test is performed to verify this assumption. Given the construction of the Anderson-Darling hypothesis test, $\mathrm{P} \geq$ 0.05 . 
Table 1. Experimental conditions for the experiments $\left(2^{3}=8\right.$ conditions $)$

\begin{tabular}{llll}
\multirow{2}{*}{ Experimental Conditions } & Experimental Factors & \\
\cline { 2 - 4 } & Silica inclusion (wt\%) & Glass fibre inclusion (wt\%) & Glass fibre length (mm) \\
\hline C1 & 5 & 15 & 5 \\
\hline C2 & 5 & 15 & 10 \\
\hline C3 & 5 & 20 & 5 \\
\hline C4 & 5 & 20 & 10 \\
\hline C5 & 10 & 15 & 5 \\
\hline C6 & 10 & 15 & 10 \\
\hline C7 & 10 & 20 & 5 \\
\hline C8 & 10 & 20 & 10 \\
\hline
\end{tabular}

Tensile and compressive tests are carried out on a Shimadzu AGX-Plus testing machine following the recommendations of the ASTM D638 ${ }^{[14]}$ and ASTM D695 ${ }^{[15]}$ standards, respectively. A $100 \mathrm{kN}$ load-cell is used, with a crosshead velocity of $3 \mathrm{~mm} / \mathrm{min}(1 \mathrm{~mm} / \mathrm{min})$ for tensile(compressive) tests. The tensile strain is obtained by a video extensometer system (Shimadzu), while the compressive strain is determined based on the crosshead displacement. The typical fracture mode of tensile samples is investigated through microstructural analysis. A Hitachi tabletop microscope (TM 3000) is used to obtain images in backscattered electron mode at $5 \mathrm{kV}$ without conductive coating.

The apparent porosity and density are determined using the ASTM C1039 standard ${ }^{[18]}$. These physical properties are obtained through the weight of dry and water-saturated samples on a $0.01 \mathrm{~g}$ precision balance. Saturation is achieved through immersion in distilled water for 24 hours, after an initial pre-saturation period of 3 hours under vacuum.

\section{Results and discussion}

Table 2 presents the average values of the physical and mechanical responses investigated for each experimental condition considering replicates 1 and 2. Table 3 shows the ANOVA analysis. Statistically significant factors (or interactions thereof) are written in bold when $\mathrm{P}$-values are less or equal to 0.05 ( $\mathrm{P}$-value $\leq 0.05)$. Underlined $\mathrm{P}$-values indicate main effects or interactions to be analysed via effect plots. The normality of the data is verified by the Anderson-Darling test (P-value $(\mathrm{AD}) \geq$
0.05 in this case), validating the ANOVA. The high values obtained for ' $\mathrm{R}^{2}$ ' indicate good predictability of the underlying statistical model used.

\subsection{Physical characterisation}

The mean values for the apparent density and porosity are shown in Table 2 . Figure 4 shows the main effect plot for the mean apparent density, which ranges from 1.143 to $1.246 \mathrm{~g} / \mathrm{cm}^{3}$. As expected, the incorporation of microparticles or fibres increases the density of the composites, due to their higher density compared to the epoxy polymer.

The interaction plot for the mean apparent porosity is presented in Figure 5. Composites with a higher amount of fibres $(20 \mathrm{wt} \%)$ and silica microparticles (10 wt $\%$ ) exhibit the highest apparent porosity (see Figure 5a). Such behaviour may be explained by the higher viscosity of the polymeric resin with higher mass fractions of reinforcements, which results in more voids in the composites. The increase in porosity is however much higher (12\%) for the higher fibre amount, being substantially smaller $(3.8 \%)$ at the lower level of fibre inclusion. For the highest mass fractions of fibre or silica, the length of the fibres does not alter the porosity substantially within the range investigated (Figure 5b and c). However, for the lower mass fractions of silica and fibres, longer fibres reduce (approx. 8\%) the porosity of the composites. Figure $5 \mathrm{c}$ shows an interaction effect between fibre amount and length factors. Reduced porosity is achieved when the lower amount of fibres (15 wt\%) is combined with longer fibres $(10 \mathrm{~mm})$. 
Table 2. Average of the physical and mechanical responses for each experimental condition

\begin{tabular}{|c|c|c|c|c|c|c|}
\hline $\begin{array}{l}\text { Experimental } \\
\text { Conditions }\end{array}$ & $\begin{array}{l}\text { Apparent } \\
\text { density } \rho_{a} \\
\left(\mathrm{~g} / \mathrm{cm}^{3}\right)\end{array}$ & $\begin{array}{l}\text { Apparent } \\
\text { porosity } \mathrm{P}_{\mathrm{a}} \\
(\%)\end{array}$ & $\begin{array}{l}\text { Compressive } \\
\text { strength } \\
\sigma_{\mathrm{c}}(\mathrm{MPa})\end{array}$ & $\begin{array}{l}\text { Compressive } \\
\text { modulus } \mathrm{E}_{\mathrm{c}}(\mathrm{MPa})\end{array}$ & $\begin{array}{l}\text { Tensile } \\
\text { strength } \\
\sigma_{\mathrm{t}}(\mathrm{MPa})\end{array}$ & $\begin{array}{l}\text { Tensile } \\
\text { modulus } E_{t} \\
(G P a)\end{array}$ \\
\hline Pure Epoxy & 1.12 & - & 56.09 & 1.79 & 35.47 & 0.67 \\
\hline $\mathrm{C} 1$ & 1.15 & 1.71 & 45.66 & 1.97 & 30.51 & 0.93 \\
\hline $\mathrm{C} 2$ & 1.14 & 1.18 & 46.92 & 1.80 & 39.05 & 0.93 \\
\hline C3 & 1.20 & 1.21 & 49.25 & 1.85 & 27.24 & 1.08 \\
\hline C4 & 1.17 & 1.54 & 49.49 & 1.93 & 36.30 & 0.87 \\
\hline C5 & 1.21 & 1.27 & 48.72 & 1.98 & 37.11 & 0.92 \\
\hline C6 & 1.19 & 1.52 & 51.17 & 2.05 & 37.66 & 1.02 \\
\hline $\mathrm{C7}$ & 1.23 & 1.67 & 43.18 & 1.70 & 31.93 & 0.97 \\
\hline $\mathrm{C} 8$ & 1.25 & 1.41 & 48.71 & 2.06 & 41.94 & 1.11 \\
\hline
\end{tabular}

Table 3. Analysis of Variance (ANOVA)

\begin{tabular}{|c|c|c|c|c|c|c|}
\hline \multirow{2}{*}{$\begin{array}{l}\text { Main Factors } \\
\text { interactions }\end{array}$} & \multicolumn{6}{|c|}{ P-value $\leq 0.05$} \\
\hline & $\rho_{a}$ & $\mathrm{P}_{\mathrm{a}}$ & $\sigma_{\mathrm{c}}$ & $E_{c}$ & $\sigma_{\mathrm{t}}$ & $E_{t}$ \\
\hline Silica mass fraction (SMF) & $\underline{0.000}$ & 0.724 & 0.661 & 0.588 & 0.303 & 0.222 \\
\hline Fibre mass fraction (FMF) & $\underline{0.015}$ & 0.147 & 0.136 & 0.802 & 0.954 & 0.048 \\
\hline Fibre length (FL) & 0.251 & 0.010 & 0.249 & 0.382 & $\underline{0.002}$ & 0.667 \\
\hline $\mathrm{SMF} * \mathrm{FMF}$ & 0.821 & 0.055 & $\underline{0.028}$ & 0.395 & 0.894 & 0.958 \\
\hline $\mathrm{SMF} * \mathrm{FL}$ & 0.517 & 0.572 & 0.140 & $\underline{0.039}$ & 0.110 & 0.002 \\
\hline $\mathrm{FMF}^{*} \mathrm{FL}$ & 0.409 & 0.161 & 0.678 & 0.067 & 0.069 & 0.249 \\
\hline $\mathrm{SMF}^{*} \mathrm{FMF}^{*} \mathrm{FL}$ & 0.298 & $\underline{0.022}$ & 0.907 & 0.908 & 0.545 & $\underline{0.013}$ \\
\hline $\mathrm{R}^{2}(\%)$ & 88.21 & 83.11 & 70.07 & 68.87 & 88.90 & 87.26 \\
\hline$P$-value $(A D) \geq 0.05$ & 0.996 & 0.569 & 0.987 & 0.942 & 0.241 & 0.979 \\
\hline
\end{tabular}

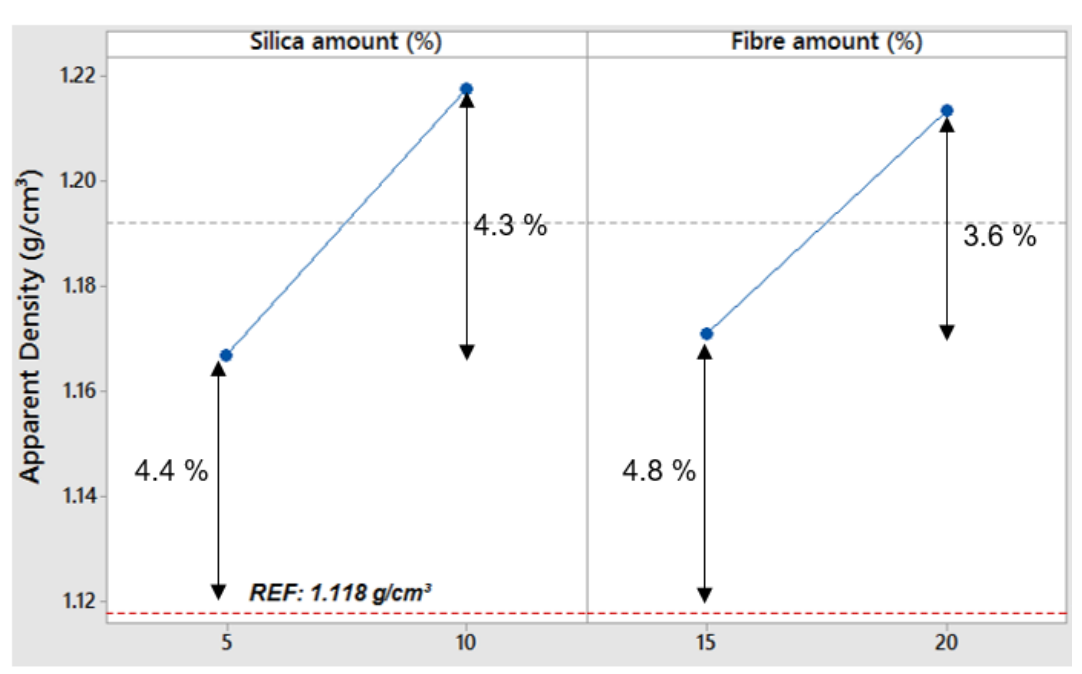

Figure 4. Main effect plots for the mean apparent density. 


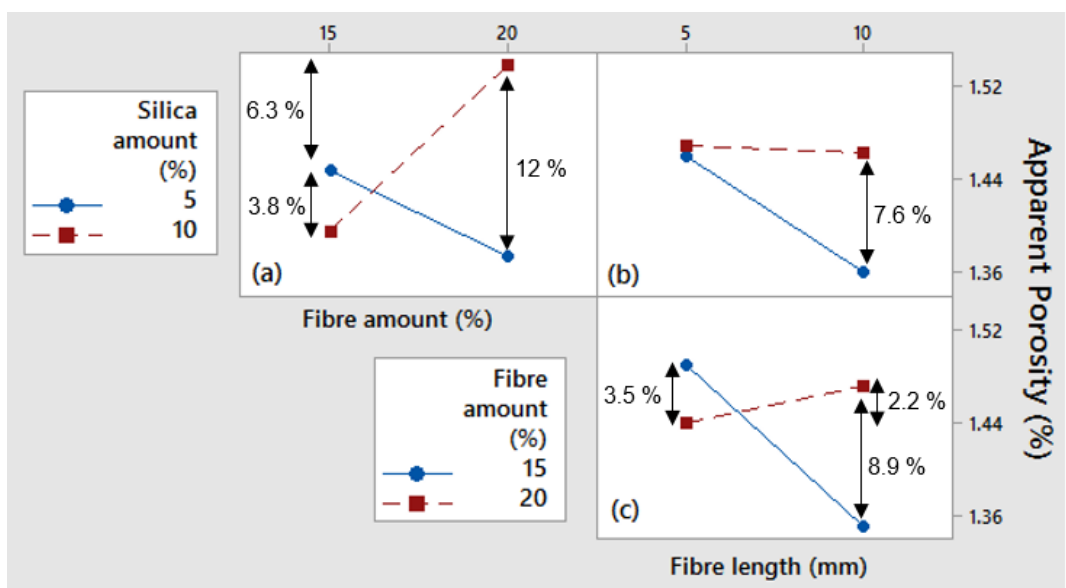

Figure 5. Interaction effects plot for the mean apparent porosity response.

\subsection{Mechanical characterisation}

The interaction plot for the mean compressive strength is shown in Figure 6. The inclusion of silica microparticles and short glass fibres decrease the compressive strength by approximately $13 \%$ compared to the pure epoxy polymer in all experimental conditions. Fibres and silica microparticles increase the viscosity of the polymeric mixture before cure and hence the porosity of the composites. The interaction of the reinforcements is complex, and further studies are yet necessary. However, it is noteworthy that composites with lower porosity provide higher compressive strength, in close agreement to the behaviour observed in Figure 5a.

The compressive modulus is significantly higher relative to pure epoxy (Figure 7). It is worth noting that the length of randomly oriented glass fibres also influenced the compressive modulus, which is higher for longer fibres at the higher mass fraction of silica microparticles (15\% higher relative to pure epoxy). Rigid sil-

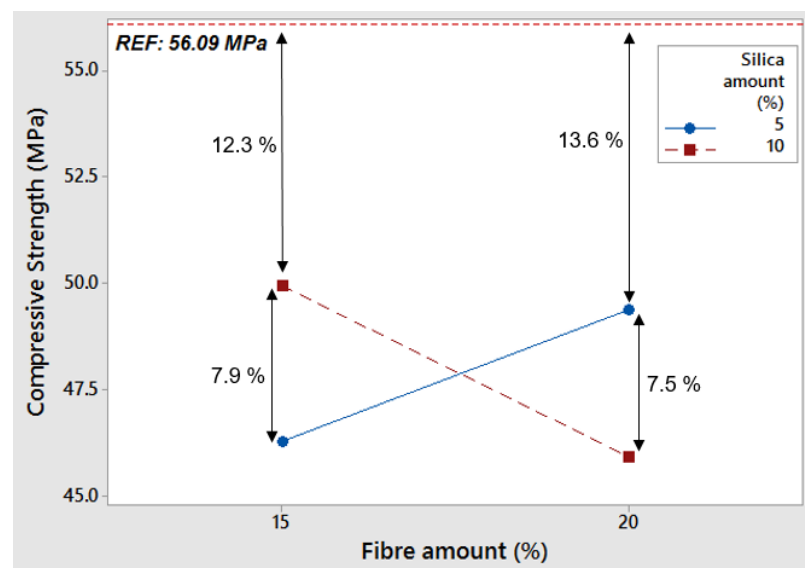

Figure 6. Interaction effects plot for the mean compressive strength response. ica particles can contribute to enhancing the compressive modulus of composites; however, this effect is not achieved for all conditions, e.g. $10 \mathrm{wt} \%$ silica with $5 \mathrm{~mm}$ long fibres, which can be attributed to the complex packing of the system.

Figure 8 shows typical compressive stress-strain curves for composites consisting of $15 \mathrm{wt} \%$ of glass fibres. The increase in fibre length, i.e. from $\mathrm{C} 1$ to $\mathrm{C} 2$ and from $\mathrm{C} 5$ to $\mathrm{C} 6$, increases the strength and toughness, the latter being considered the area under the curve. It should also be noted that the incorporation of $10 \mathrm{wt} \%$ of silica (C5 and C6) provides greater compressive strength compared to $\mathrm{C} 1$ and $\mathrm{C} 2$ made with $5 \mathrm{wt} \%$, as shown in Figure 6 . The pure epoxy polymer presents higher compressive strength. In some cases, composites were able to achieve longer deformations than pure polymers, being attributed to the delay in the propagation of cracks due to the fibre and particle inclusions.

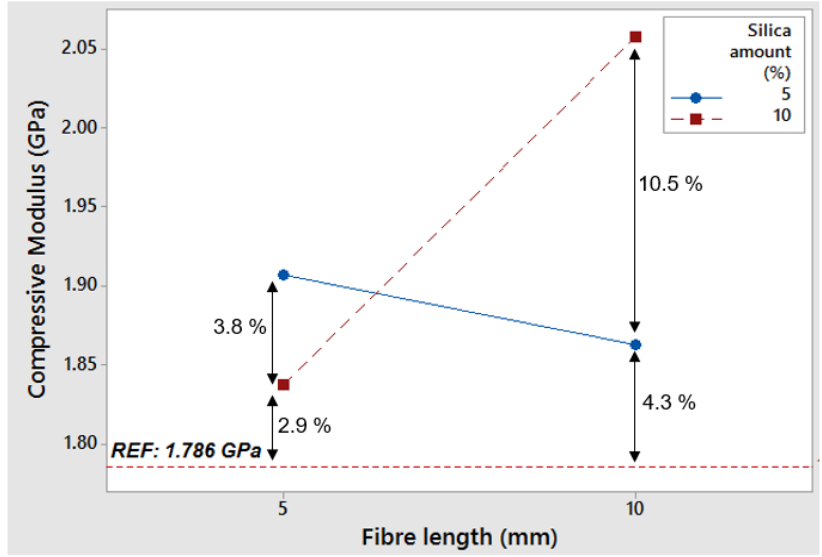

Figure 7. Interaction effects plot for the mean compressive modulus response. 


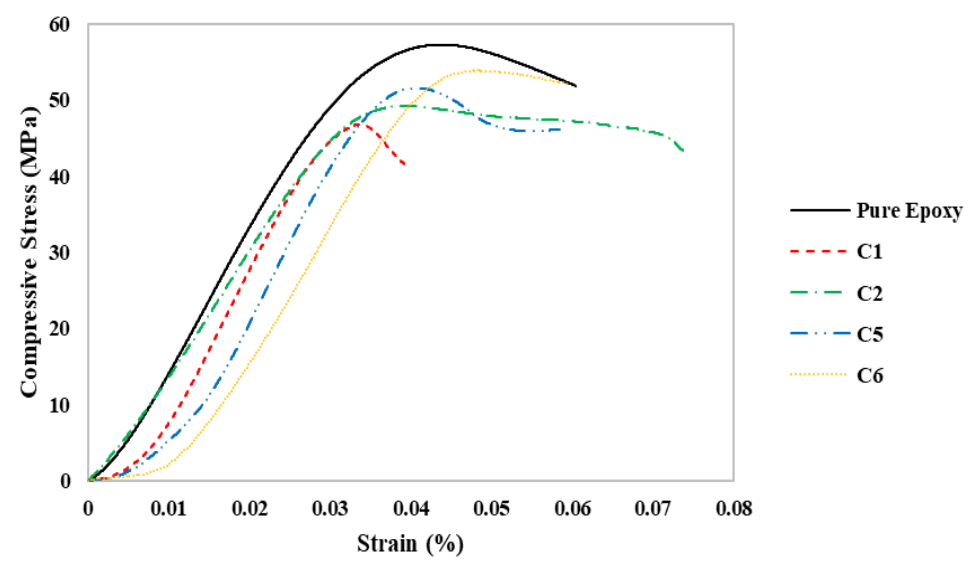

Figure 8. Typical compressive stress-strain curves for samples made with $15 \mathrm{wt} \%$ of glass fibres.

The length of the fibres significantly influences the tensile strength of the hybrid composites (Figure 9), as already described in the literature ${ }^{[1,9]}$. Both authors reported that fibre ends are loci of high-stress concentrations, as previously discussed in the introduction section. Our results corroborate this statement, since longer fibres increase the tensile strength of the pure epoxy composites in $9 \%$, while shorter fibres decrease it in $11 \%$. For a given fibre mass fraction, $5 \mathrm{~mm}$-long fibres provide twice as many stress concentrations sites than $10 \mathrm{~mm}$ long ones, so that the tensile strength is $22 \%$ higher for longer fibres relative to the shorter ones.

The incorporation of short glass fibres and silica microparticles substantially increases the tensile modulus relative to pure epoxy (Figure 10). The enhancement is higher (approx. 57\%) for the higher amount of longer fibres and microparticles (10 wt\%) as shown in Figure 10a. For the lower silica amount, longer fibres reduce tensile modulus and contribute with a slight modulus increase with higher fibre mass fraction (Figures 10a and 10b). For the longer glass fibres, the amount of fibres does not affect the tensile modulus significantly, whereas smaller fibres at higher amounts contribute to enhancing that response (Figure 10c). Particles and fibres acting as composite reinforcement present a positive interaction, contributing to higher composite stiffness ${ }^{[2]}$, compared to the neat polymer.

Figure 11 shows the typical tensile stress-strain curves for samples made with $10 \mathrm{wt} \%$ of silica. The tensile strength and toughness (based on the area under the curves) increase with fibre length. This behaviour is apparent, especially for conditions $\mathrm{C} 7$ and $\mathrm{C} 8$ with the higher fibre volume fraction (20 wt $\%)$. In general, the reinforcements lead to higher elastic modulus and strength, and lower strain to failure relative to the pure polymer at pure condition, as shown in Figure 11. All composites present fragile rupture, characterised by a sudden drop in stress, while the pure polymer displays a small decay in tensile stress before failure (Figure 11).

Figure 12 shows the microstructural analysis of the fractured surfaces of composites C6 (a-b) and C8(c-d) after the tensile test at $\times 30$ and $\times 100$ magnification levels. These composites are made of $10 \mathrm{wt} \%$ of silica and 15 wt\% (C6) and $20 \mathrm{wt} \%$ (C8) of $10 \mathrm{~mm}$ fibres. All compositions reveal a similar fracture mode, with typical fibre pull-out. Macroscopic bubbles are also observed (see dark spots shown by the arrows), mainly in C8 made with less amount of matrix phase, which evidences the mixing problems during the manufacturing process owing to the higher viscosity of the mixture. 


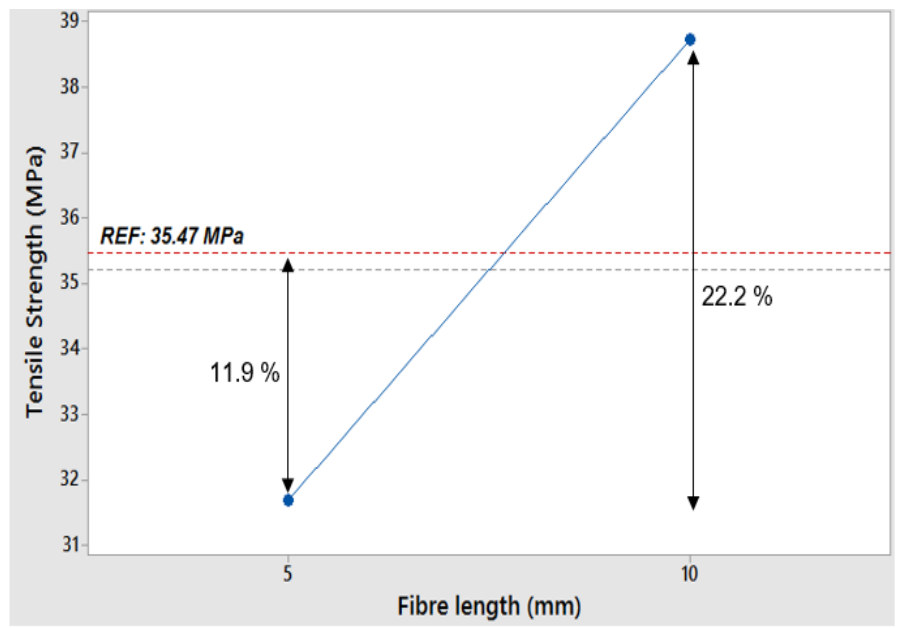

Figure 9. Main effect plot for the mean tensile strength response.

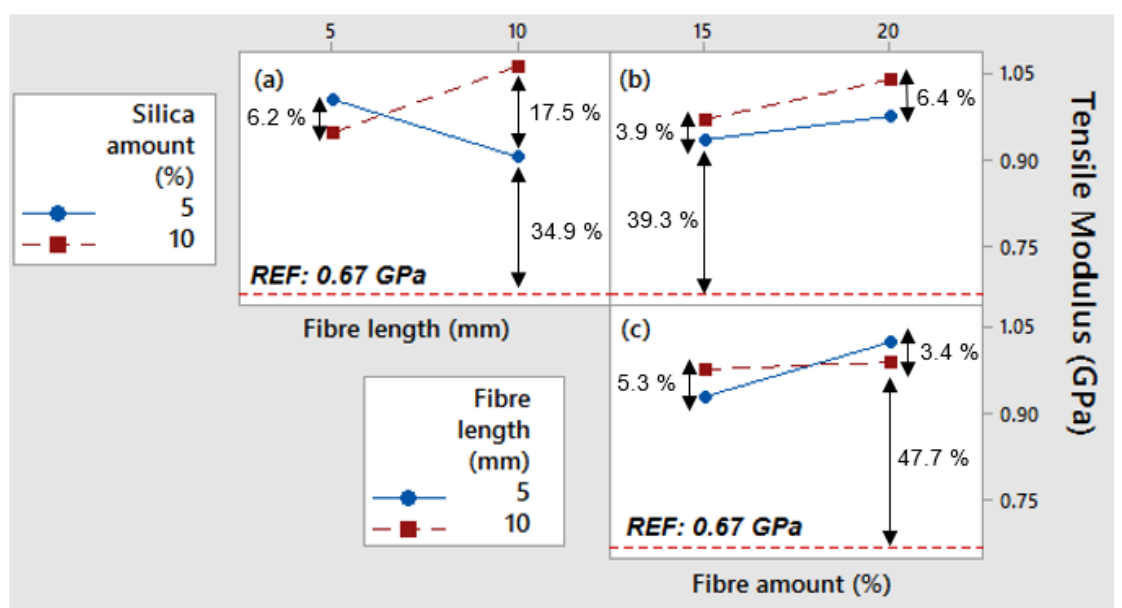

Figure 10. Interaction effects plot for the mean tensile modulus response.

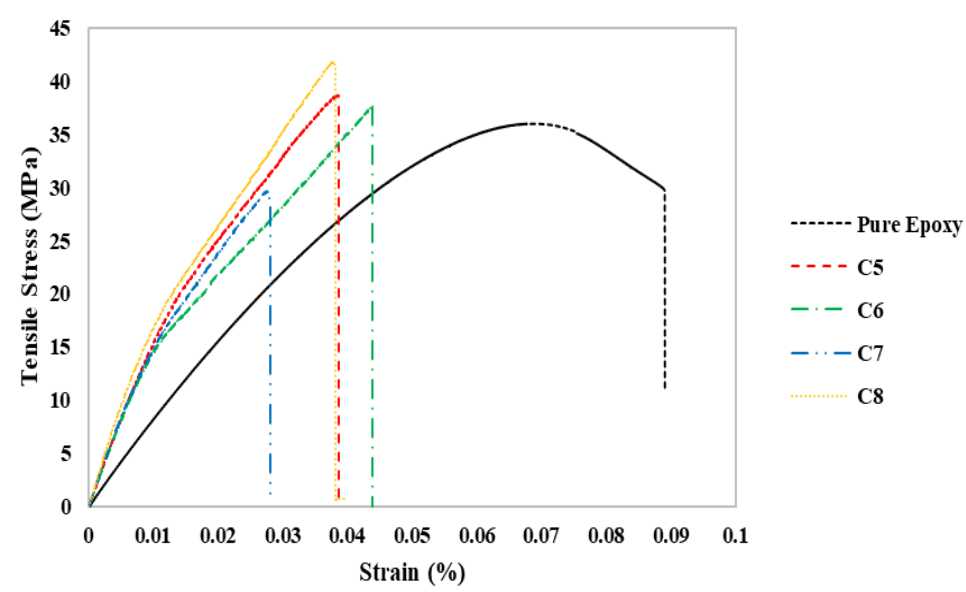

Figure 11. Typical tensile stress-strain curves for samples made with $10 \mathrm{wt} \%$ of silica particles. 

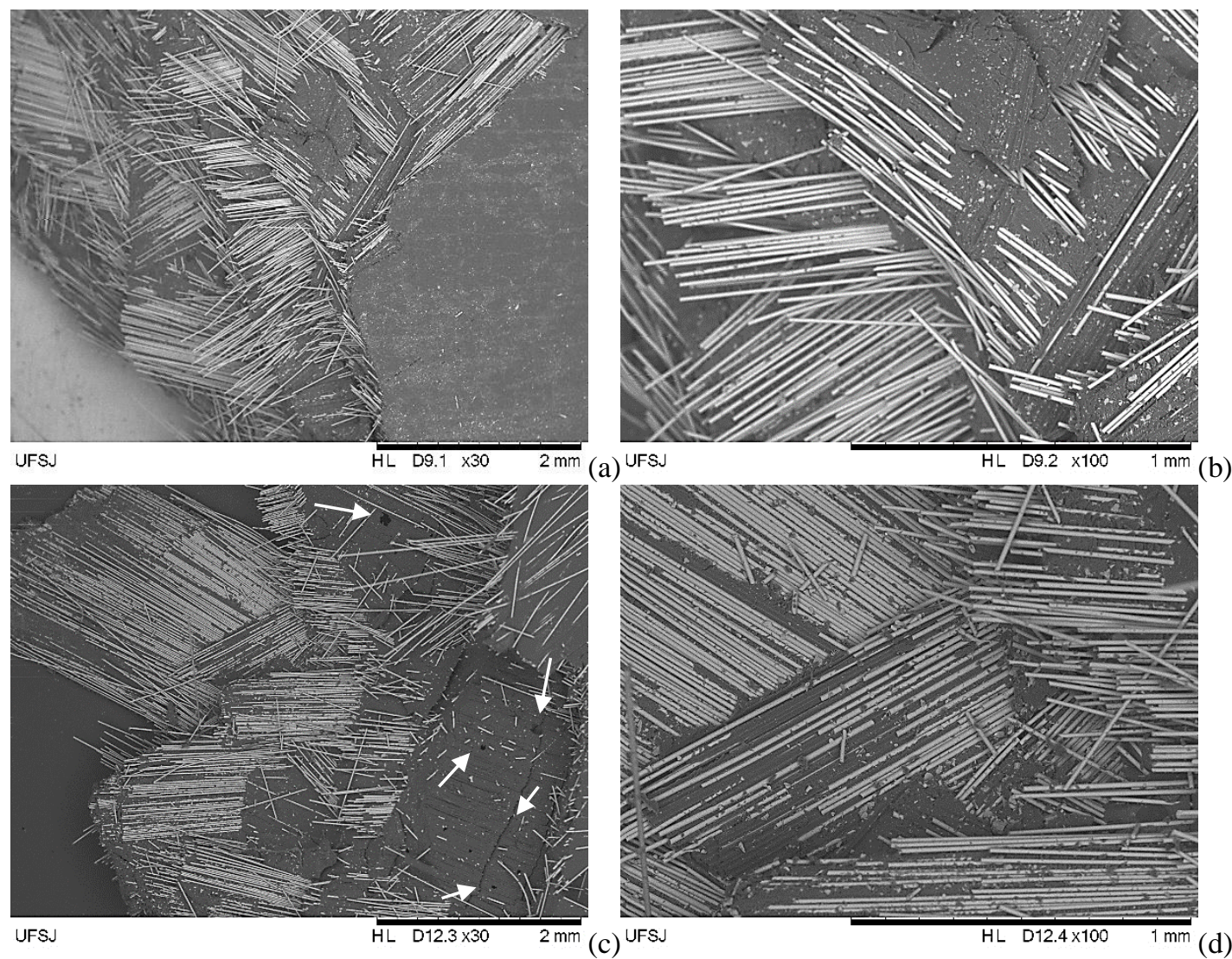

Figure 12. Backscattering Electron Images (BEI at 5kV) of C6 (a-b) and C8 (c-d) composites after tensile test.

\section{Conclusion}

This work investigates the effects of different mass fractions of silica microparticles and short glass fibres along with varying lengths of fibre on the apparent density and porosity of epoxy composites. The compressive and tensile moduli and strengths are also evaluated. The main findings are summarised as follows:

1. The apparent density of hybrid composites is higher (4.4\%-9.1\%) upon the inclusion of the fillers, as expected;

2. The compressive strength of the hybrid composites is at least $10 \%$ lower relative to pure epoxy composites, which can be related to the apparent porosity, ranging from $1.36 \%$ to $1.52 \%$;

3. The compressive modulus increases up to $15 \%$ upon the incorporation of the fillers used;

4. The tensile strength increases $9 \%$ in longer fibre $(10 \mathrm{~mm})$ hybrid composites, while shorter (5 mm) fibres decrease it in $11 \%$. For a given fibre mass fraction, $5 \mathrm{~mm}$-long fibres provide twice as many stress-concentration sites than
$10 \mathrm{~mm}$ long ones, so that the tensile strength is $22 \%$ higher for longer fibres relative to the shorter ones;

5. The increase in fibre length from 5 to $10 \mathrm{~mm}$ leads to increased tensile and compressive toughness of the composites;

6. The tensile modulus of hybrid composites is up to $57 \%$ higher relative to pure epoxy;

7. The fracture mode in tensile testing is dominated by the fibre pull-out effect with fragile rupture.

In summary, epoxy composites reinforced by short, randomly oriented glass fibres and silica microparticles present significantly higher tensile strength and modulus as well as compressive strength relative to pure epoxy.

\section{Author contributions}

LAJ (Investigation, Writing-original draft preparation); RTSF (Writing-Reviewing and Editing); PRO (Reviewing, Data curation); ALC (Supervision, Methodology); CTG (Resources); GGP (Data curation); THP (Supervision, Conceptualization, Methodology). 


\section{Conflict of interest}

The authors report no conflict of interest.

\section{Acknowledgements}

The authors acknowledge the support of the Brazilian Research Agencies, CNPq-Brazil (PQ309885/2019-1) and CAPES (MSc scholarship), and the donations from Moinhos Gerais Company (Brazil).

\section{References}

1. Fu SY, Lauke B, Ma“der E, et al. Tensile properties of short-glass-fiber-and short-carbon-fiber-reinforced polypropylene composites. Composites: Part A 2000; 31: 1117-1125.

2. Patnaik A, Satapathy A, Chand N, et al. Solid particle erosion wear characteristics of fiber and particulate filled polymer composites: A review. Wear 2010; 268(1-2): 249-263.

3. Santos JC, Vieira LM, Panzera TH, et al. Hybrid glass fibre reinforced composites with micro and poly-diallyldimethylammonium chloride (PDDA) functionalised nano silica inclusions. Materials \& Design 2015; 65: 543-549.

4. Detomi AC, Santos RM, Filho SL, et al. Statistical effects of using ceramic particles in glass fibre reinforced composites. Materials \& Design 2014; 55 : 463-470.

5. Torres RB, Santos JC, Panzera TH, et al. Hybrid glass fibre reinforced composites containing silica and cement microparticles based on a design of experiment. Polymer Testing 2017; 57: 87-93.

6. Pande SJ, Sharma DK. Strength and stiffness of short glass fibre/glass particulate hybrid composites. Fibre Science and Technology 1984; 20: 235-243.

7. Oliveira LA, Santos JC, Panzera TH, et al. Evaluation of hybrid-short-coir-fibre-reinforced composites via full factorial design. Composite Structures 2018; 202: 313-323.

8. Santos FM, Batista FB, Panzera TH, et al. Hybrid composites reinforced with short sisal fibres and micro ceramic particles. Revista Matéria 2017; 22: (2).

9. Curtis PT, Bader MG, Bailey JE. The stiffness and strength of a polyamide thermoplastic reinforced with glass and carbon fibres. Journal of Materials Science 1978; 13: 377-390.

10. Doshi SR, Charrier JM. A simple illustration of structure-properties relationships for short fiber-reinforcedthermoplastics. Polymer Composites 1989; 10(1): 28-38.

11. Srivastava VK. Effect of filler on fracture of short glass fibre reinforced epoxy resin. Engineering
Fracture Mechanics 1989; 33(1): 113-119.

12. Nikpur K, Chen YF, Kardos JL. Fracture toughness of unidirectional short-fiber reinforced epoxy composites. Composites Science and Technology 1990; 38: 175-191.

13. Reis JML, Ferreira AJM. Assessment of fracture properties of epoxy polymer concrete reinforced with short carbon and glass fibers. Construction and Building Materials 2004; 18: 523-528.

14. ASTM D638-14, Standard test method for tensile properties of plastics. ASTM International 2003.

15. ASTM D695-15, Standard test method for compressive properties of rigid plastics 1. ASTM International 2002.

16. Cao Y. Impact properties of silica particle modified glass fiber reinforced epoxy composite. Journal of Reinforced Plastics and Composites 2006; 25(7): 761-769.

17. Montgomery DC. Introduction to statistical quality control. USA: John Wiley \& Sons; 1997.

18. ASTM C1039-85, Standard test methods for apparent porosity, apparent specific gravity, and bulk density of graphite electrodes. ASTM International 2015. 